\title{
Leukocyte larceny: a cause of pseudohypoxemia
}

\author{
Omar Pardesi, MD (1) Edward A. Bittner, MD, PhD
}

Received: 24 May 2016/Revised: 13 June 2016/Accepted: 20 June 2016/Published online: 28 June 2016

(C) Canadian Anesthesiologists' Society 2016

A 74-yr-old woman presented with dyspnea, fatigue, and abdominal pain. Central laboratory analysis showed a white blood cell count of $664,000 / \mathrm{mm}^{3}$ and hematocrit of $11.5 \%$. Imaging revealed a large, solid, retroperitoneal mass with hemorrhagic conversion that was uneventfully treated with arterial embolization. However, her arterial blood gases (ABG) in the operating room and postoperatively while intubated consistently showed hypoxemia with an arterial oxygen tension $\left(\mathrm{PaO}_{2}\right)$ of 37$60 \mathrm{mmHg}$. Surprisingly, this situation occurred despite a pulse oximetry saturation of $98-100 \%$. In addition, the $\mathrm{PaO}_{2}$ did not increase despite the administration of $100 \%$ oxygen and multiple ventilation adjustments.

The differential diagnosis for blood gas hypoxemia with a normal pulse oximetry saturation is limited but includes inadvertent venous blood sampling, delay between blood draw and its analysis, air bubbles in the sample, ABG device malfunction, and an elevated white blood cell count. ${ }^{1}$ This final cause, referred to as "leukocyte larceny," is thought to result from leukocytes in the sample consuming oxygen before analysis occurs, leading to a spuriously low $\mathrm{PaO}_{2} \cdot{ }^{1,2}$ The patient's blood smear (Figure) shows impressive leukocytosis, consistent with a new diagnosis of chronic myelogenous leukemia, as the cause of the retroperitoneal mass and spurious hypoxemia. Leukocytes of various lineages, but in particular an excessive number of immature blast cells, were present in her peripheral blood. These immature cells consume far more oxygen than mature cells. ${ }^{3}$

O. Pardesi, MD $(\varangle) \cdot$ E. A. Bittner, MD, PhD

Department of Anesthesia, Critical Care, and Pain Medicine,

Massachusetts General Hospital, Boston, MA, USA

e-mail: opardesi@partners.org
This pseudohypoxemia due to leukocyte larceny can be identified by adding cyanide to sample. ${ }^{2}$ The cyanide normalizes the $\mathrm{PaO}_{2}$ by inhibiting mitochondrial respiration. Point-of-care or continuous blood gas measurements could also identify true $\mathrm{PaO}_{2}$ before the white blood cells can consume the oxygen in vitro. ${ }^{3} \mathrm{An}$ easier, more practical approach includes using pre-cooled ABG syringes to slow oxygen consumption and accurately measure $\mathrm{PaO}_{2}{ }^{3}$ Alternatively, one can simply use pulse oximetry to gauge oxygenation. ${ }^{1-3}$ Recognizing leukocytosis as a cause of spurious hypoxemia may allow

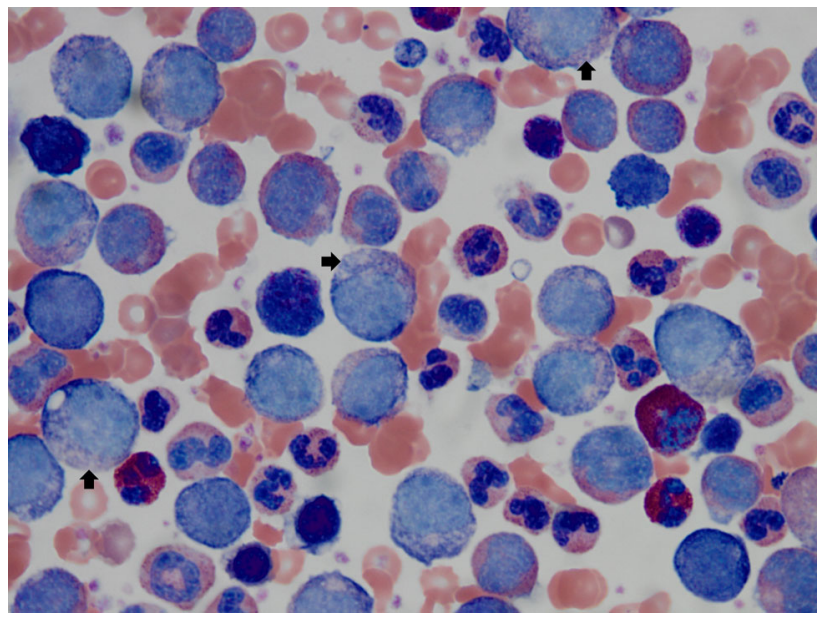

Figure The blood smear from this 74-yr-old patient with chronic myelogenous leukemia and associated massive leukocytosis $(664,000 /$ $\mathrm{mm}^{3}$ ) who presented with a $\mathrm{PaO}_{2}$ of $37-60 \mathrm{mmHg}$ despite a pulse oximetry saturation of $98-100 \%$. The excessive immature blast cells (arrows) resulted in this pseudohypoxemia due to the oxygen consumption by the blast cells in the arterial blood gas sample that occurred between the time of the sample draw until analysis, thus representing a case of "leukocyte larceny" 
providers to avoid further invasive techniques, such as additional arterial blood draws or bronchoscopy. It also provides reassurance that such patients may continue to be safely weaned from ventilator support when moving toward extubation.

Acknowledgement Philip D. Poorvu, MD, Clinical Fellow, Department of Hematology \& Oncology, Massachusetts General Hospital/Partners CancerCare Program, Boston, Massachusetts, USA.

Funding No funding was received in connection with this manuscript.

Conflicts of interest None declared.
Editorial responsibility This submission was handled by Dr. Hilary P. Grocott, Editor-in-Chief, Canadian Journal of Anesthesia.

\section{References}

1. Lele AV, Mirski MA, Stevens RD. Spurious hypoxemia. Crit Care Med 2005; 33: 1854-6.

2. Fox MJ, Brody JS, Weintraub LR. Leukocyte larceny: a cause of spurious hypoxemia. Am J Med 1979; 67: 742-6.

3. Prasad KN, Manjunath P, Priya L, Sasikumar S. Overcoming the problem of pseudohypoxemia in myeloproliferative disorders: another trick in the bag. Indian J Crit Care Med 2012; 16: 210-2. 